\title{
Interdecadal Variability of Rossby Wave Breaking Frequency near Japan in August
}

\author{
Kazuto Takemura ${ }^{1,2}$, Hitoshi Mukougawa ${ }^{1}$, and Shuhei Maeda ${ }^{3}$ \\ ${ }^{1}$ Graduate School of Science, Kyoto University, Kyoto, Japan \\ ${ }^{2}$ Climate Prediction Division, Japan Meteorological Agency, Tokyo, Japan \\ ${ }^{3}$ Aerological Observatory, Japan Meteorological Agency, Tsukuba, Japan
}

\begin{abstract}
Rossby waves propagating along the Asian jet frequently cause the breaking near the jet exit region. This study examines characteristics of oceanographic condition and atmospheric circulation associated with interdecadal variability of Rossby wave breaking frequency near Japan in August. Sea surface temperature during a period of the higher Rossby wave breaking frequency is cooler over the central part of the tropical North Pacific, compared with that during a period of the lower frequency. Convective activities are suppressed over the region consistent with the cooler sea surface temperature, contributing to an enhanced and southwestward extended mid-Pacific trough. Deceleration and diffluence of the Asian jet are stronger during the period of the higher frequency than that during the period of the lower one. The enhanced deceleration and diffluence of the jet are associated with the enhanced and southwestward extended mid-Pacific trough. The abovementioned dynamical influence is also shown by a numerical simulation using an atmospheric linear baroclinic model. These results indicate that the interdecadal variability of sea surface temperature over the central part of the tropical North Pacific has an impact on that of the Rossby wave breaking frequency near Japan, through the modulated convective activities and midPacific trough.
\end{abstract}

(Citation: Takemura, K., H. Mukougawa, and S. Maeda, 2021: Interdecadal variability of Rossby wave breaking frequency near Japan in August. SOLA, 17, 125-129, doi:10.2151/sola.2021-021.)

\section{Introduction}

In boreal summer, Rossby wave propagation along the Asian jet (e.g., Enomoto et al. 2003) frequently causes wave breaking (RWB) near the jet exit region from Japan to the east (e.g., Postel and Hitchman 1999; Abatzoglou and Magnusdottir 2006). Takemura et al. (2020) showed a close relationship between interannual variability of the RWB frequency near Japan and that of monthly-averaged temperature over northern to western Japan in August. They also indicated an influence of El Niño Southern Oscillation (ENSO) on the interannual variability of the RWB frequency near Japan. Although they further showed an existence of decadal-like variability in the RWB frequency over the region, the associated mechanism of the long-term variability was not revealed. Strong and Magnusdottir (2009) indicated that the frequent RWB over the North Pacific can cause variations of sea surface temperature (SST) over the region and the consequent phase modulation of Pacific decadal oscillation (PDO; Mantua et al. 1997). Besides the impact of the RWB frequency near Japan on the PDO phase, the impact of PDO-related SST variability on the RWB frequency near Japan is also expected. This study thus examines characteristics and factors of interdecadal variability of the RWB frequency near Japan using long-term atmospheric and oceanographic dataset. This line of approach is important to elucidate a process for long-term variability of summer climate near Japan.

Corresponding author: Kazuto Takemura, Graduate School of Science, Kyoto University, Kitashirakawa Oiwake-cho, Sakyo, Kyoto 606-8502, Japan. E-mail: takemura.kazuto@kugi.kyoto-u.ac.jp.

\section{Data and methods}

Daily and monthly mean datasets of the Japanese 55-year reanalysis (JRA-55; Kobayashi et al. 2015) in August during 61-yr period from 1958 to 2018 , with a horizontal resolution of $1.25^{\circ}$ and 37 pressure levels from 1000 to $1 \mathrm{hPa}$, are used to analyze large-scale atmospheric circulation. To analyze the SST, we used monthly mean dataset of COBE-SST (Ishii et al. 2005) for the same month during the $61-\mathrm{yr}$ period with a resolution of $1^{\circ}$. To infer convective activities in tropics, we also used monthly dataset of outgoing long-wave radiation (OLR) in August during 40-yr period from 1979 to 2018 , with a resolution of $2.5^{\circ}$, provided by National Oceanic and Atmospheric Administration. To compare the interdecadal variability of the RWB frequency with the PDO, monthly PDO index provided by Japan Meteorological Agency is used. To exclude long-term warming trend of the SST and height fields in the JRA-55, linear trends during the 61-yr period are subtracted from the inter-annual variabilities.

To calculate the RWB frequency near Japan, we utilized a daily blocking index (Pelly and Hoskins 2003) based on distribution of potential temperature $\theta$ on the dynamical tropopause defined by 2 potential vorticity unit (PVU; $1 \mathrm{PVU}=10^{-6} \mathrm{~K} \mathrm{~kg}^{-1} \mathrm{~m}^{2} \mathrm{~s}^{-1}$ ). The blocking index $\mathrm{B}$ is expressed as follows:

$$
B=\frac{1}{\Delta \lambda} \int_{-\Delta \lambda / 2}^{\Delta \lambda / 2}\left\{\frac{2}{\Delta \phi}\left(\int_{\phi_{0}}^{\phi_{0}+\Delta \phi / 2} \theta d \phi-\int_{\phi_{0}-\Delta \phi / 2}^{\phi_{0}} \theta d \phi\right)\right\} d \lambda
$$

where $\lambda$ is the longitude, $\Delta \lambda$ is the width of zonal average, $\phi$ is the latitude, $\Delta \phi$ is the typical meridional scale of the RWB, and $\phi_{0}$ is the central latitude. We defined $\Delta \lambda$ as $5^{\circ}$ and $\Delta \phi$ as $30^{\circ}$, respectively, according to Pelly and Hoskins (2003). A daily RWB is detected when $B$ has a positive value: there is high (low) $\theta$ to the north (south). Monthly RWB frequency is defined as the ratio of a number of days on which the RWB is detected in the month.

\section{Results}

\subsection{Interdecadal variability of $R W B$ frequency near Japan}

Gray-colored bars in Fig. 1a show interannual time-series of areal-averaged RWB frequency near Japan $\left(25^{\circ} \mathrm{N}-45^{\circ} \mathrm{N}, 130^{\circ} \mathrm{E}-\right.$ $160^{\circ} \mathrm{E}$ ) in August during the period from 1958 to 2018 . The $11-\mathrm{yr}$ running-mean RWB frequency (blue line in Fig. 1a) over the region clearly shows its interdecadal variability around a longterm trend (red dashed line). According to interdecadal phases of the RWB frequency, periods of the three phases are defined with the higher frequency during a period from 1967 to 1982 and a period from 2004 to 2013, and the lower frequency during a period from 1983 to 2003 (background warm- and cold-colored shadings of a graph in Fig. 1a). From the 11-yr running-mean monthly PDO index in August (blue line in Fig. 1b), it is found that the PDO phases (background color of a graph in Fig. 1b) precede the interdecadal phases for the RWB frequency (that in Fig. 1a) with a few years. The possible factor for the difference of the interdecadal phases will be discussed in Section 3.4. 
(a) RWB Frequency

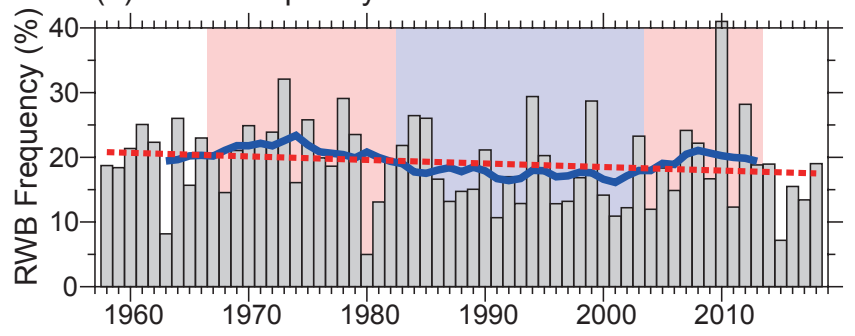

(b) PDO Index

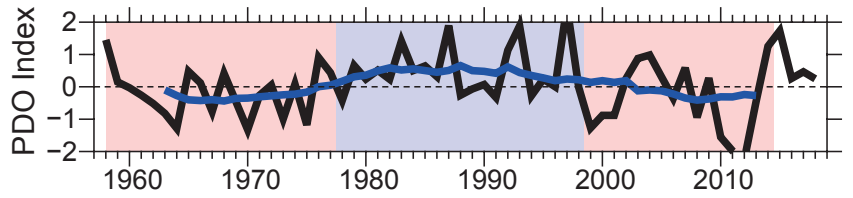

Fig. 1. Inter-annual time series of (a) areal averaged RWB frequency over $25^{\circ} \mathrm{N}-45^{\circ} \mathrm{N}, 130^{\circ} \mathrm{E}-160^{\circ} \mathrm{E}$ (bars; unit: \%) and (b) PDO index in August during 61-yr period from 1958 to 2018. Blue lines show the 11-yr running mean. Red dashed line in (a) indicates a linear regression line of the RWB frequency during the 61-yr period. Background colors in each graph show the interdecadal phases defined according to the 11-yr running mean (blue lines).

\subsection{Characteristics of large-scale atmospheric circulation asso- ciated with interdecadal phase of $R W B$ frequency near Japan}

To examine differences in the oceanographic condition and atmospheric circulation in August between the period with the higher RWB frequency and that with the lower one, differences of time-averages in the month between the period of 1967-1982, 2004-2013 (1979-1982, 2004-2013 for the OLR) and that of 1983-2003 are shown in this section, according to available period of the OLR dataset since 1979.

The difference of SST (Fig. 2a) shows positive changes near the mid-latitude North Pacific, and negative changes over the central to eastern tropical Pacific, consistent with a change of the PDO phase from positive to negative. The SST cooling over the central part of the tropical North Pacific (region A shown in Fig. 2a) is significantly seen associated with the phase shift of the PDO. The difference of OLR (Fig. 2b) shows inert convective activities over a wide area in the central tropical Pacific, which is associated with the cooling SST over the region (Fig. 2a). A statistical relationship between the SST and the OLR will be shown in Section 3.4.

Hereafter an influence of the inert convective activities over the central part of the tropical North Pacific on the uppertropospheric atmospheric circulation over the North Pacific is examined. In low-latitudes, the difference of 200-hPa height (Fig. 3a) shows negative changes over a wide area from the southeast of Japan to the central part of the tropical North Pacific. The region, where the upper-level descending height tendency is seen, corresponds to that where the climatological trough is located (contour in Fig. 3a), indicating an enhanced and southwestward extended mid-Pacific trough. In mid-latitudes, the difference of $200-\mathrm{hPa}$ height clearly shows the wavy pattern, particularly over Eurasia with the large differences. These large differences suggest an existence of interdecadal variability in the quasi-stationary Rossby wave along the Asian jet accompanied with meridional gradient of the height field (contour in Fig. 3a). It is also consistent with the results of Wang et al. (2017) and Maeda and Tanaka (2020), who indicated interdecadal variations of the Silk Road pattern (Enomoto et al. 2003)

Here the Asian jet exit region near Japan corresponds to northwestern periphery of the climatological mid-Pacific trough (Fig. $3 a)$. Hence it is presumed that the enhanced and southwestward extended mid-Pacific trough can contribute to the increased RWB frequency near Japan through enhanced deceleration and diffluence of the Asian jet. To verify this process, the difference of 200-

(a) Difference of SST

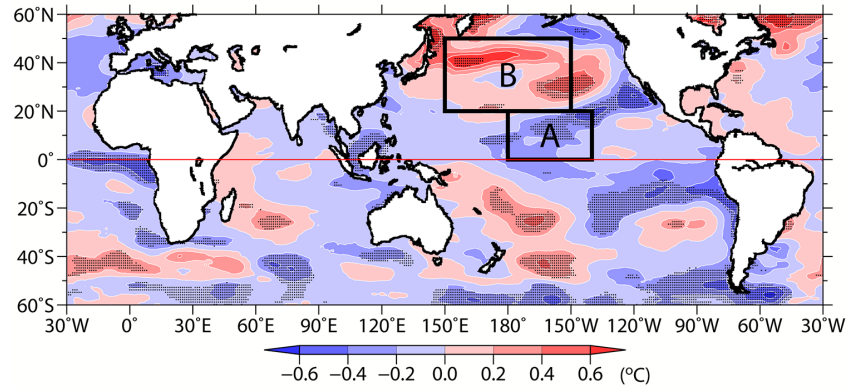

(b) Difference of OLR

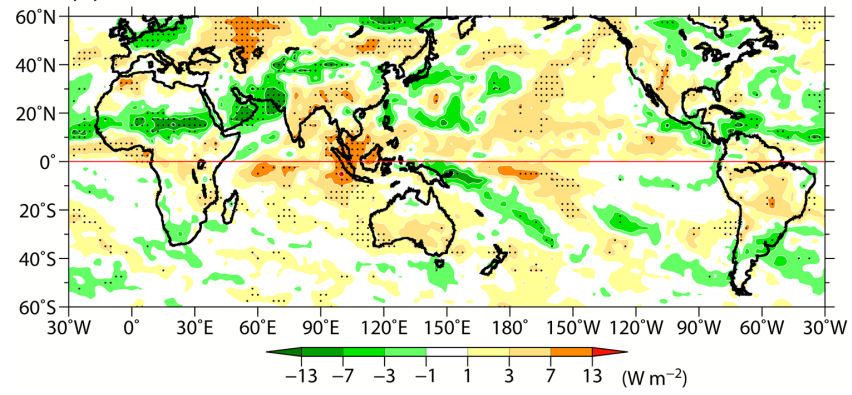

Fig. 2. Differences in time-averages of (a) SST between the period of 1967-1982, 2004-2013 and that of 1983-2003, (b) OLR between the period of 1979-1982, 2004-2013 and that of 1983-2003 in August. Dots indicate that the differences are statistically significant at the confidence level of $95 \%$. In (a), areas surrounded by black lines labeled by "A" and "B" denote the areas to assess areal-averaged SST.

(a) Difference of Z200

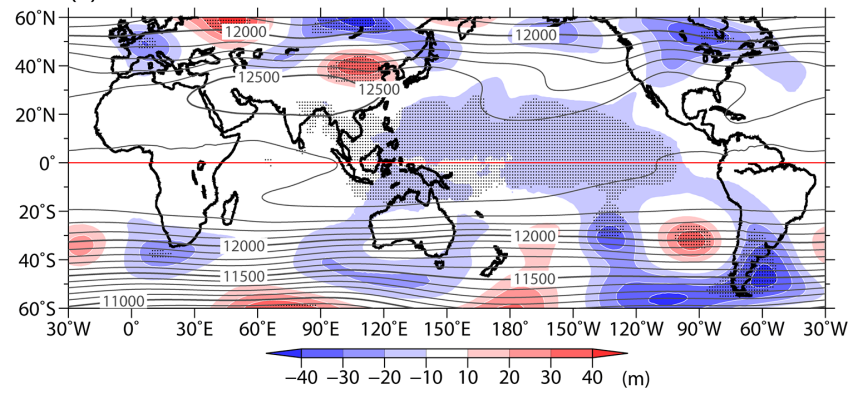

(b) Difference of SD200

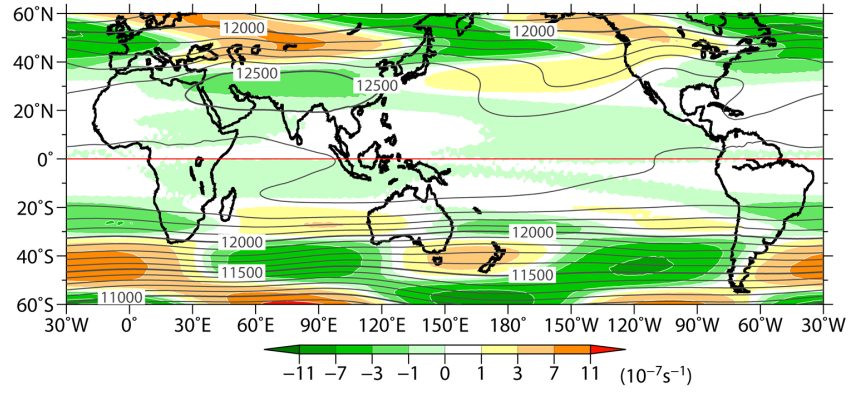

Fig. 3. Same as in Fig. 2, but for (a) 200-hPa height, and (b) $200-\mathrm{hPa}$ stretching deformation of basic state between the period of 1967-1982, 2004-2013 and that of 1983-2003. Contour lines indicate the climatological height at $200 \mathrm{hPa}$ averaged during 61-yr period from 1958 to 2018 in August.

hPa stretching deformation (Mak and Cai 1989; Bluestein 1992) of basic state derived from time-averaged horizontal winds is shown in Fig. 3b. Here the basic state is defined as zonal wavenumber $k<3$, and the stretching deformation $d_{B}$ is defined as follows: 


$$
d_{B} \equiv \frac{\partial u_{B}}{\partial x}-\frac{\partial v_{B}}{\partial y}
$$

Here $u_{B}$ and $v_{B}$ are zonal and meridional winds of the basic state, respectively. Negative $d_{B}$ indicates deceleration and diffluence fields. The difference of 200-hPa $d_{B}$ shows negative changes near Japan to the west (shading in Fig. 3b), indicating the enhanced deceleration and diffluence of the Asian jet over the region, corresponding to the northwestern periphery of the enhanced and southwestward extended mid-Pacific trough (Fig. 3a). The arealaveraged $d_{B}$ at $200 \mathrm{hPa}$ over $25^{\circ} \mathrm{N}-45^{\circ} \mathrm{N}, 130^{\circ} \mathrm{E}-160^{\circ} \mathrm{E}$ has a negative correlation with the areal-averaged RWB frequency over the region at a confidence level of $99 \%$ (not shown). This result indicates that the strong jet deceleration and diffluence in the upper troposphere are associated with the increased RWB frequency near Japan. The enhanced deceleration and diffluence of the Asian jet exit may also be partly associated with the above-mentioned interdecadal variability of the wavy pattern over Eurasia (Fig. 3a).

These results indicate that the inert convective activities over the central part of the tropical North Pacific associated with the PDO-related SST cooling can influence the interdecadal increase in the RWB frequency, through the enhanced deceleration and diffluence of the Asian jet near Japan.

\subsection{LBM experiment}

To clarify an impact of the inert convective activities over the central part of the tropical North Pacific on the atmospheric circulation in the upper troposphere, a numerical experiment using a linear baroclinic model (LBM; Watanabe and Kimoto 2000, 2001) is conducted. The LBM comprises primitive equations linearized about the 61-yr averages from 1958 to 2018 in August, and uses the spherical harmonics method with a horizontal resolution of T42 and 20-sigma levels in the vertical direction. The model has a Newtonian damping to mimic boundary-layer processes, with the damping time scale of 1 day for the lowest three and topmost two levels, 5 and 15 day for the fourth and fifth levels, and 30 day elsewhere.

In the LBM experiment, the difference in time-averaged diabatic heating rate of the JRA-55 between the period of 1967-1982, 2004-2013 and that of 1983-2003 in August over the central part of the tropical Pacific $\left(10^{\circ} \mathrm{S}-30^{\circ} \mathrm{N}, 160^{\circ} \mathrm{E}-120^{\circ} \mathrm{W}\right.$; surrounded by green dashed box in Fig. 4a) is given as a steady forcing. The vertically-integrated heat forcing is shown in Fig. 4a. Height at $200 \mathrm{hPa}$ in the experiment (shading in Fig. 4b) shows negative responses around a latitude band of $20^{\circ} \mathrm{N}$ over the Pacific due to the diabatic cooling near the central part of the tropical North Pacific (Fig. 4a). The height response has the same order with that of the difference shown in Fig. 3a, indicating the enhanced and southwestward extended mid-Pacific trough due to the inert convective activities over the region. The negative height response at $200 \mathrm{hPa}$ indicates that atmospheric responses to a wide area of the suppressed convection over the central part of the tropical Pacific are dominant, although zonally-elongated enhanced convection is partly seen along the latitudinal band of $10^{\circ} \mathrm{N}$. Similar amplitude of the height response is obtained even if the damping time scale is altered (not shown). Figure $4 \mathrm{c}$ further shows the response of $200-\mathrm{hPa}$ stretching deformation of the basic state, which is derived from the horizontal wind during the period from 1983 to 2003 added with the response. The upper-level stretching deformation shows a negative response near Japan to the west, consistent with the difference of the stretching deformation presented in Fig. 3b, indicating the enhanced deceleration and diffluence of the Asian jet near Japan. The strong negative response of the upper-level stretching deformation is also clearly seen over mid-latitude Eurasia, which is inconsistent with the difference of the stretching deformation (Fig. 3b). This suggests that the difference of the stretching deformation over Eurasia (Fig. 3b) is associated with the interdecadal variability of the wavy pattern over the region (Fig. 3a), supporting the suggestion described in Section 3.2. The response of the $200-\mathrm{hPa}$ height and stretching deformation to the global heat forcing also indicates the enhanced and southwestward (a) Difference of Heating Rate

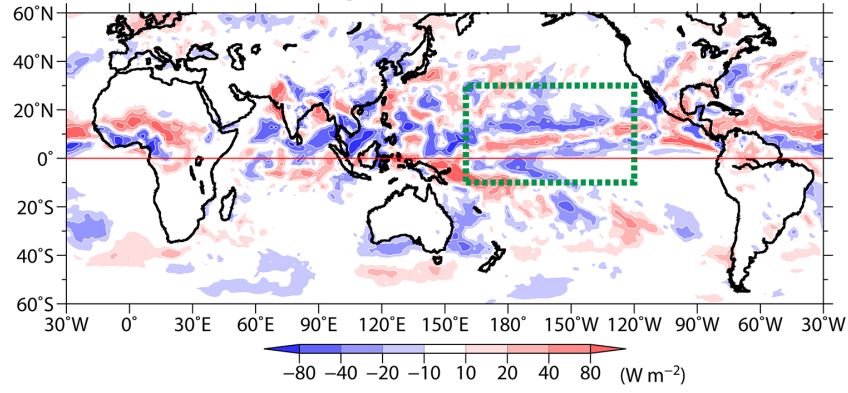

(b) Response of $Z 200$

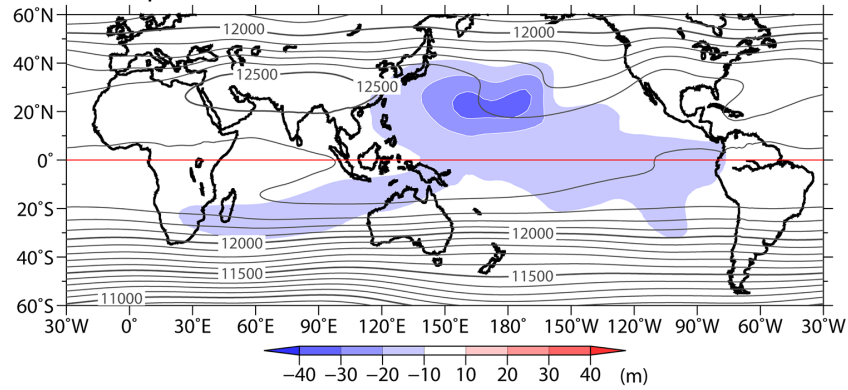

(c) Response of SD200

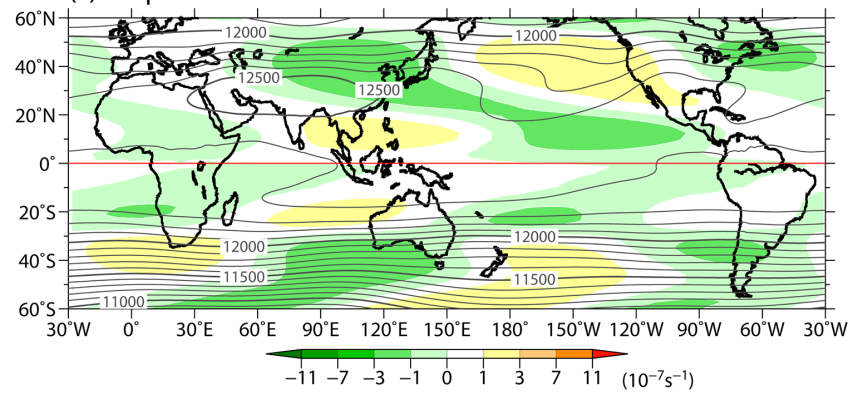

Fig. 4. (a) Difference in time-averaged vertically-integrated diabatic heating rates between the period of 1967-1982, 2004-2013 and that of 19832003 in August, and linear responses of (b) 200-hPa height (unit: m) and (c) 200-hPa stretching deformation of the basic state (unit: $10^{-7} \mathrm{~s}^{-1}$ ) (shading) in LBM experiment. Contour lines indicate the climatological height at $200 \mathrm{hPa}$ averaged during 61-yr period from 1958 to 2018 in August.

extended mid-Pacific trough and the associated enhanced deceleration and diffluence of the Asian jet near Japan (not shown). The response of the stretching deformation to the global heat forcing is quite similar with that to the heat forcing for the central part of the tropical North Pacific (Fig. 4c). It is presumably due to the dominant response with the zonal wavenumber $k<3$ to the zonally-elongated diabatic cooling over the region surrounded by green dashed box in Fig. 4a.

These results indicate that the inert convective activities over the central part of the tropical North Pacific can contribute to the enhanced deceleration and diffluence of the Asian jet near Japan through the enhanced and southwestward extended mid-Pacific trough, supporting the results shown in Section 3.2.

\subsection{Interdecadal Phases of SST and RWB frequency}

This section discusses a possible factor for the difference of the interdecadal phases between the RWB frequency near Japan (Fig. 1a) and the PDO index (Fig. 1b) described in Section 3.1. The results shown in Section 3.2 imply that the interdecadal variability of the RWB frequency near Japan can be attributable to that of the SST over the central part of the tropical North Pacific, which is partly associated with the PDO. To assess the abovementioned relationship, interannual time-series of areal-averaged SST over the central part of the tropical North Pacific (region A in 
(a) Central Tropical North-Pacific

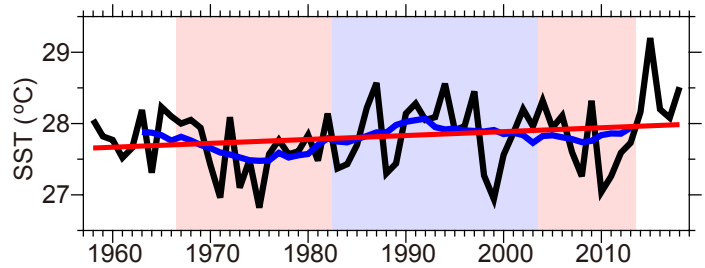

(b) Mid-Latitude North-Pacific

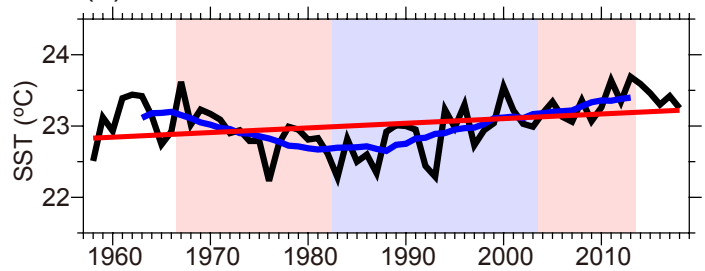

Fig. 5. Inter-annual time series of areal averaged SST (unit: ${ }^{\circ} \mathrm{C}$ ) near (a) the central part of the tropical North Pacific $\left(0^{\circ} \mathrm{N}-20^{\circ} \mathrm{N}, 180^{\circ} \mathrm{W}-140^{\circ} \mathrm{W}\right.$; region A in Fig. 2a) and (b) the mid-latitude North Pacific $\left(20^{\circ} \mathrm{N}-50^{\circ} \mathrm{N}\right.$, $150^{\circ} \mathrm{E}-150^{\circ} \mathrm{W}$; region B in Fig. 2a) in August during 61-yr period from 1958 to 2018 . Blue lines show the 11-yr running mean. Red lines indicate linear regression lines during the 61-yr period. Background colors in each graph show the interdecadal phase of the RWB frequency (i.e., same as in Fig. 1a).

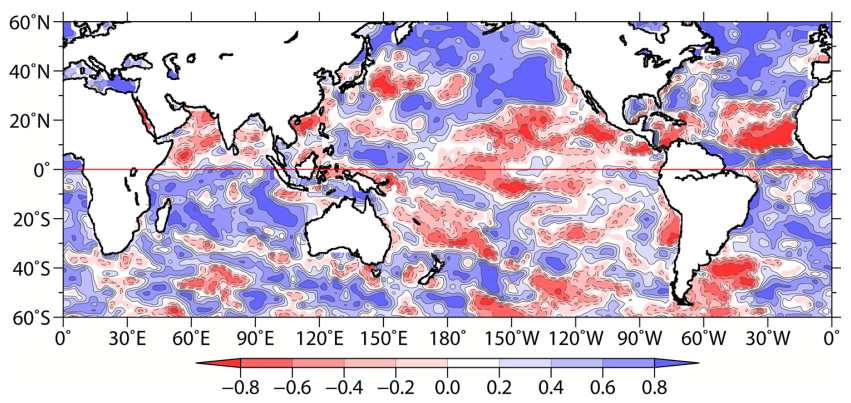

Fig. 6. Correlation coefficients between 11-yr running mean SST and OLR in August during 30-yr period from 1984 to 2013 with a contour interval of 0.2 . Resolution of the SST dataset is linearly interpolated from $1^{\circ}$ to $2.5^{\circ}$, and the correlation coefficient is derived at each grid point.

Fig. 2a) and the mid-latitude North Pacific (region B in Fig. 2a) is shown in Figs. 5a and 5b, respectively. The SSTs over both regions indicate not only the significant warming trends (red lines) but also the interdecadal variabilities with the different phases (blue lines). The interdecadal phase of the RWB frequency near Japan (background colors of graphs in Fig. 5) is more synchronous with the SST over the central part of the tropical North Pacific (Fig. 5a) than that over the mid-latitude North Pacific (Fig. 5b). This result indicates that the interdecadal variability of the RWB frequency near Japan is strongly associated with that of the PDO-related SST over the central part of the tropical North Pacific, supporting the result shown in Section 3.2.

To assess a relationship between the SST and the convective activities near the central part of the tropical North Pacific with the interdecadal time scale, correlation coefficients between the SST and the OLR during the period from 1984 to 2013 in August are shown in Fig. 6. Here the SST and the OLR are derived from the 11-yr running mean of the interannual variabilities in August. The resolution of SST dataset is linearly interpolated from $1^{\circ}$ to $2.5^{\circ}$, and the correlation coefficient is derived at each grid point. The negative correlation near the central part of the tropical North Pacific (red-colored shading in Fig. 6) indicates that the cooler SSTs are associated with the suppressed convective activities over the region with the interdecadal time scale, supporting the results

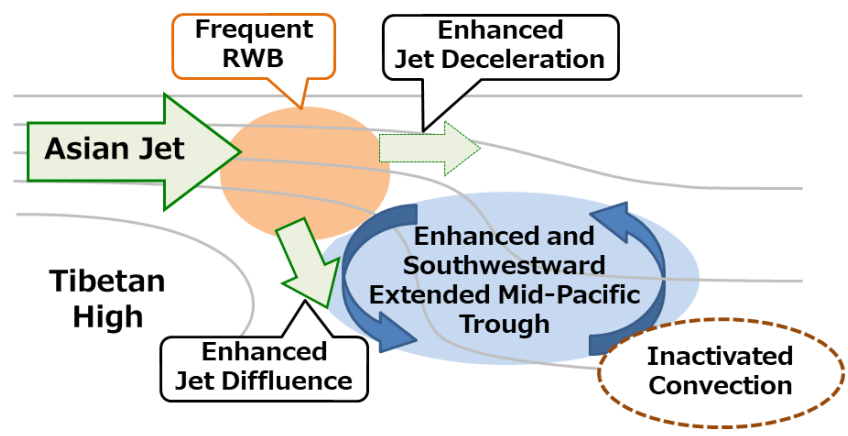

Fig. 7. A simplified schematic diagram describing dynamical influence of inactivated convection related to SST cooling over the central tropical Pacific on increased RWB frequency near Japan, through suppressed convective activities and the consequent enhanced and southwestward extended mid-Pacific trough.

in this section and the relationship between the cooling SST and the inert convective activities (Figs. 2a and 2b) described in Section 3.2.

\section{Conclusion and discussion}

This study examined the characteristics of oceanographic condition and atmospheric circulation associated with the interdecadal variability of the RWB frequency near Japan in August. Compared with the SST during the period of the lower RWB frequency, the SST during the period of the higher frequency was cooler over the central tropical Pacific. The convective activities were suppressed over the central part of the tropical Pacific in association with the cooling SST, contributing to the enhanced and southwestward extended mid-Pacific trough. The deceleration and diffluence of the Asian jet were stronger during the period of the higher RWB frequency, associated with the enhanced and southward extended mid-Pacific trough. The above-mentioned dynamical influence of the inert convective activities over the central part of the tropical North Pacific on the upper-level atmospheric circulation over the North Pacific was also shown by numerical experiments using the LBM. The dynamical influence of the inactivated convection related to the SST cooling over the central tropical Pacific on the increase in the RWB frequency near Japan is schematically summarized in Fig. 7.

These results indicate that the interdecadal variability of SST over the tropical Pacific has an impact on that of the RWB near Japan, through the modulated convective activities and mid-Pacific trough. The result described in Section 3.4 suggests that the RWB frequency near Japan is associated not with the SST variability over the mid-latitude North Pacific but with that over the central part of the tropical North Pacific, also supporting the above-mentioned result. This result also shows a validity to assess the relationship of the RWB frequency near Japan to the SST variability over specific regions in the North Pacific, as presented in Fig. 5. The dynamical process summarized in Fig. 7 is common in both the inter-annual time scale (Takemura et al. 2020) and the interdecadal time scale described in this study, although the anomalous SST patterns, which affect the RWB frequency near Japan, are different between the two time-scales. A further detailed investigation is thus required to clarify a reason for the similar modulations of the RWB frequency near Japan resulting from the different SST patterns between the two different time scales.

The inter-annual time series of RWB frequency near Japan (Fig. 1a) further shows the decreased tendency after 2013, consistent with the significantly positive PDO index (Fig. 1b). The large positive PDO index from 2014 to 2015 is partly related to meridional gradient of SST with the negative (positive) anomalies to the south (north) of the equator over the central to eastern Pacific in 2014 (e.g., Maeda et al. 2016a) and a subsequent strong 
El Niño event during a period from summer 2014 to spring 2016 winter. These anomalous features of the SST since 2014 will motivate us to further examine a relationship between the RWB frequency near Japan and Pacific meridional mode of the SST (PMM; Chiang and Vimont 2004). Maeda et al. (2016b) revealed that an enhanced intertropical convergence zone during summer to fall of 2014, which is associated with the PMM, can contribute to the shallower mid-Pacific trough, suggesting the further impact on the RWB frequency near Japan.

\section{Acknowledgements}

The authors are very grateful to an editor Prof. R. Kawamura and two anonymous reviewers for their constructive and helpful comments. The Generic Mapping Tools (GMT) were used to create the graphics. This study was partly supported by the JSPS KAKENHI Grant (18H01280, 18K03734).

Edited by: R. Kawamura

\section{References}

Abatzoglou, J. T., and G. Magnusdottir, 2006: Planetary wave breaking and nonlinear reflection: Seasonal cycle and interannual variability. J. Climate, 19, 6139-6152.

Bluestein, H. B., 1992: Synoptic-Dynamic Meteorology in Midlatitudes. Vol. 1, Oxford University Press, $431 \mathrm{pp}$.

Chiang, J. C. H., and D. J. Vimont, 2004: Analogous Pacific and Atlantic meridional modes of tropical atmosphere-ocean variability. J. Climate, 17, 4143-4158.

Enomoto, T., B. J. Hoskins, and Y. Matsuda, 2003: The formation mechanism of the Bonin high in August. Quart. J. Roy. Meteor. Soc., 129, 157-178.

Ishii, M., A. Shouji, S. Sugimoto, and T. Matsumoto, 2005: Objective analyses of sea-surface temperature and marine meteorological variables for the 20th century using ICOADS and the Kobe collection. Int. J. Climatol., 25, 865-879.

Kobayashi, S., Y. Ota, Y. Harada, A. Ebita, M. Moriya, H. Onoda, K. Onogi, H. Kamahori, C. Kobayashi, H. Endo, K. Miya- oka, and K. Takahashi, 2015: The JRA-55 Reanalysis: General specifications and basic characteristics. J. Meteor. Soc. Japan, 93, 5-48.

Mak, M., and M. Cai, 1989: Local barotropic instability. J. Atmos. Sci., 46, 3289-3311.

Maeda, S., Y. Urabe, K. Takemura, T. Yasuda, and Y. Tanimoto, 2016a: Active role of the ITCZ and WES feedback in hampering the growth of the expected full-fledged El Niño in 2014. SOLA, 12, 17-21.

Maeda, S., Y. Urabe, K. Takemura, T. Yasuda, and Y. Tanimoto, 2016b: Significant atmospheric circulation anomalies over the North Pacific associated with the enhanced ITCZ during the summer-fall of 2014. SOLA, 12, 282-286.

Maeda, S., and M. Tanaka, 2020: Preprints of the MSJ annual scientific meetings (Spring 2020), 138 pp (in Japanese).

Mantua, N. J., S. R. Hare, Y. Zhang, J. M. Wallace, and R. C. Francis, 1997: A Pacific Interdecadal Climate Oscillation with impacts on salmon production. Bull. Amer. Meteor. Soc., 78, 1069-1079.

Pelly, J. L., and B. J. Hoskins, 2003: A new perspective on blocking. J. Atmos. Sci., 60, 743-755.

Postel, G. A., and M. H. Hitchman, 1999: A climatology of Rossby wave breaking along the subtropical tropopause. J. Atmos. Sci., 56, 359-373.

Strong, C., and G. Magnusdottir, 2009: The role of tropospheric Rossby wave breaking in the Pacific Decadal Oscillation. $J$. Climate, 22, 1819-1833.

Takemura, K., H. Mukougawa, and S. Maeda, 2020: Large-scale atmospheric circulation related to frequent Rossby wave breaking near Japan in boreal summer. J. Climate, 33, 67316744.

Wang, L., P. Xu, W. Chen, and Y. Liu, 2017: Interdecadal variations of the Silk Road pattern. J. Climate, 30, 9915-9932.

Watanabe, M., and M. Kimoto, 2000: Atmospheric-ocean thermal coupling in the North Atlantic: A positive feedback. Quart. J. Roy. Meteor. Soc., 126, 3343-3369.

Watanabe, M., and M. Kimoto, 2001: Corrigendum. Quart. J. Roy. Meteor. Soc., 127, 733-734.

Manuscript received 22 February 2021, accepted 30 April 2021

SOLA: https://www.jstage.jst.go.jp/browse/solal 